\title{
Design universal aplicado no desenvolvimento conceitual de ducha doméstica
}

Universal design applied in the conceptual development of a

domestic shower

\section{Eduarda Werner}

Universidade Federal de Santa Catarina

eduardawerner@hotmail.com

Glaucia Inácio Martins

Universidade Federal de Santa Catarina

glauciamartins96@gmail.com $\mathbf{x}$

Ivan Luiz de Medeiros

Universidade Federal de Santa Catarina

ivanmedeiros75@gmail.com

PROJËTICA

\section{COMO CITAR ESTE ARTIGO:}

WERNER, Eduarda; MARTINS, Glaucia Inácio; MEDEIROS, Ivan Luiz de. Design universal aplicado no desenvolvimento conceitual de ducha doméstica. Projética, Londrina, v. 12, n. 1, p. 270-296, 2021.

DOI: 10.5433/2236-2207.2021v12n1p270

Submissão: 30-03-2019

Aceite: 12-12-2019 
RESUMO: O objetivo deste estudo é trazer os principais pontos contribuintes para o desenvolvimento conceitual de uma ducha doméstica inclusiva e não-estigmatizada. A ascensão desse segmento de produtos tem crescido consideravelmente e está diretamente ligada aos princípios do Design Universal. Para a metodologia, utilizouse o Design Thinking, onde os resultados aqui apresentados consistem em um processo de desenvolvimento de produto centrado no usuário, repercutindo em uma proposta de chuveiro que contemple necessidades de uma população pouco prestigiada em acessibilidade de produtos.

Palavras-chave: Design universal. Desenvolvimento de produto. Ducha doméstica. Produto inclusivo.

ABSTRACT: The goal of this research is bringing the main contribution aspects to the conceptual development of an inclusive and non-stigmatized domestic shower. The growth of this product segment is directly linked to the principles of Universal Design. The Design Thinking was used as methodology, in which the results achieved consist of a usercentered product development process, reflecting on a shower proposal that addresses the needs of an audience that is often neglected regarding products' accessibility.

Keywords: Universal design. Product development. Domestic shower. Inclusive product.

\section{INTRODUÇÃO}

Ao desenvolver um novo produto deve-se pensar muito além da solução para uma pessoa específica, pois é necessário que este objeto satisfaça as necessidades física e cognitiva de um grande grupo evitando causar restrições e frustrações quanto ao seu uso. Desta maneira é recomendado que haja uma quebra de estigmas a fim de não constranger nenhum indivíduo com suas particularidades. Produtos e 
serviços que atendam todos os tipos de público e cenário estão sendo cada vez mais utilizados.

A acessibilidade é um termo que muito já se ouve falar, seja nos espaços, produtos ou serviços. Esses últimos, porém, nem sempre agradam ao usuário e acabam por se tornar objetos com custos de produção e comercialização elevados, que priorizam sua funcionalidade e deixam a estética de lado.

Corroborando com este pensamento inicial dos pesquisadores pode-se citar Norman (2008), quando afirma que a estética e a funcionalidade devem andar juntas para que a experiência do usuário seja completa. O mesmo autor aponta que existem três níveis emocionais: o visceral, comportamental e reflexivo. O nível visceral diz respeito à primeira impressão do usuário com o produto e o que aquele produto desperta quando visto, esse nível geralmente ocorre pela aparência e é de maior abrangência de público. O segundo nível, comportamental, relaciona-se ao uso do produto e a satisfação que temos ao concluir uma ação com o mesmo. 0 nível reflexivo é um pensamento que vem antes e depois, podendo ser influenciado por fatores externos como culturais e temporais. Trata-se de uma avaliação feita sobre o produto e se ele é realmente um bom objeto para ser utilizado. Os produtos devem, então, atender os aspectos de uso e forma.

Conforme os estudos de Alvarenga (2006), o projeto inclusivo consiste na identificação das necessidades e desejos dos usuários e requisitos de projeto de forma a expandi-los, avaliá-los e propor uma nova concepção de produto. $\mathrm{O}$ processo de inclusão deve ser tratado em paralelo com o projeto proposto e se preocupa diretamente em alcançar uma menor exclusão de usuários incluindo crianças, jovens, idosos, pessoas com deficiência, necessidades especiais, etc.

Seguindo esses pensamentos, esta pesquisa aborda diretamente a problemática dos cadeirantes no uso do banheiro e volta-se, mais especificamente, 
à ação de tomar banho. A proposta de projeto se estende também a idosos e grávidas já que possuem limitações semelhantes entre si, sendo contemplados pela proposta advinda da problematização de cadeirantes.

Segundo dados do IBGE, 6,2\% da população declarou ter pelo menos um tipo de deficiência, seja do tipo visual, auditiva, motora ou mental/intelectual. Entre esses, boa parte necessita de cadeira de rodas para se locomover (VILLELA, 2015).

Muitos lugares públicos carecem de rampa de acessibilidade e é evidente o tamanho da problematização que isso causa. O problema se torna ainda mais nítido na falta de produtos adaptados na casa do indivíduo, fazendo com que haja dificuldade ao realizar tarefas básicas diárias (lavar a louça, lavar e estender a roupa, etc). Nesse viés se percebe a urgência de se projetar para usuários com limitações físicas já que é notável o desconforto desses ao utilizar produtos padronizados pelo mercado.

Pensando nisso, faz-se necessário a criação de um produto esteticamente agradável e que cumpra os requisitos de usabilidade para o cadeirante, no momento do banho.

Este trabalho possui pesquisa de natureza aplicada (FLEURY; WERLANG, 2016) com abordagem qualitativa, seus objetivos são descritivos e os procedimentos técnicos utilizados consistiram na aplicação da metodologia do Design Thinking.

A abordagem do Design Thinking trabalha com cinco etapas que serão demonstradas no decorrer do artigo, sendo: a 1) empatia, que busca observar a temática do Design Universal e a relação com o público cadeirante, 2) definição do foco, que estreita a relação entre o que se pretende atingir e a forma que isso poderá ser feita, 3) ideação, onde será definida a melhor opção de produto que cumpra com todos pontos desejáveis da pesquisa e 4) prototipação, que dará aos 
pesquisadores maior conhecimento do tamanho real do objeto e sua proporção. Na figura abaixo (fig. 1), as etapas aparecem de forma objetiva.

Figura 1 - Etapas do Design Thinking aplicadas ao projeto

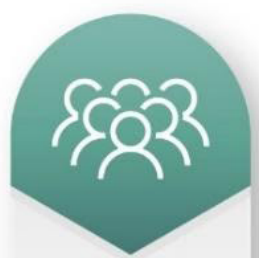

EMPATIA

Design Universal

Público cadeirante

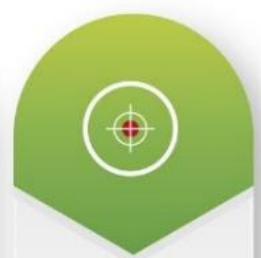

FOCO

Ducha doméstica inclusiva

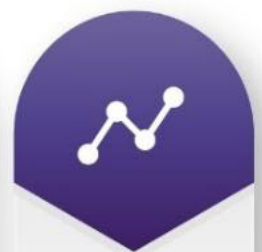

IDEAÇÃO

Escolha de melhor alternativa de ducha doméstica inclusiva

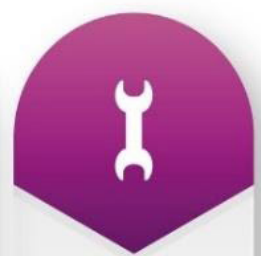

PROTOTIPAÇÃO

Modelo físico da ducha doméstica inclusiva

Fonte: dos autores, 2018.

Portanto, o objetivo geral do trabalho é propor conceitualmente uma ducha doméstica inclusiva com abordagens do Design Universal e, de forma específica, a) compreender a problemática existente ao público cadeirante, b) analisar os conceitos do Design Universal, c) verificar a importância da acessibilidade no momento do banho e, por último, d) desenvolver conceitualmente uma ducha de banho doméstica esteticamente agradável. 


\subsection{O Design Thinking como Metodologia de Projeto}

A partir da metodologia é possível traçar os principais pontos da pesquisa e seguir uma sequência lógica para chegar em uma solução. Os métodos são imprescindíveis para que um projeto seja feito, portanto não se deve pensar artisticamente, mas seguir uma metodologia de forma a entender cada etapa do processo de projeto (MUNARI, 1998).

Além de centrar sua preocupação no usuário, com o Design Thinking é possível contemplar uma variedade de indivíduos já que "[...] um conjunto de princípios podem ser aplicados por diversas pessoas a uma ampla variedade de problemas" (BROWN, 2010, p. 6). Estudos demonstram que o uso do Design Thinking tem alcançado bons resultados na criação de produtos, projetos, modelos e serviços (BROWN, 2008). Sendo assim, a metodologia do Design Thinking torna possível gerar produtos e experiências reais.

Como já abordado na introdução, o desenrolar do presente projeto apresentará, paralelamente, as etapas de empatia, definição, ideação e prototipação.

\section{REVISÃO DE LITERATURA}

\subsection{Design Universal}

Neste contexto de pesquisa, com uma abordagem centrada no ser humano, buscou-se como referência projetual compreender e aplicar os conceitos do Design Universal. Sendo esse um termo imprescindível no que diz respeito à criação de um produto voltado para o maior público possível, faz-se necessário um maior aprofundamento sobre o tema. 
O Design Universal é um elemento essencial na criação, desenvolvimento e utilização de um produto ou espaço inclusivo. Ele está diretamente ligado às políticas que visam atender a todos os usuários sem causar estranheza. Conforme Francisco e Menezes (2011), o Design Universal se constitui dos seguintes princípios básicos: a) equiparação nas possibilidades de uso, b) flexibilidade no uso, c) uso simples e intuitivo, d) captação da informação, e) tolerância para o erro, e f) dimensão e espaço para uso e interação.

A expressão Design Universal foi utilizada pela primeira vez em 1985 pelo arquiteto Ron Mace, influenciador da mudança de paradigma no desenvolvimento de projetos urbanos, arquitetura e design - principalmente de produtos. Segundo Mace, Hardie e Place (1991), o Design Universal consiste na criação de ambientes ou produtos que possam ser utilizados por todas as pessoas em sua máxima extensão possível.

A proposta de projeto do chuveiro deve, portanto, cumprir com os requisitos básicos de um produto inclusivo e ser, entre outros pontos, de uso intuitivo e fácil entendimento.

\subsection{Acessibilidade}

Quando se adere ao Design Universal como uma vertente de pesquisa é importante lembrar que ele possui uma abordagem para qualquer indivíduo, independentemente de suas limitações. Segundo a NBR 9050 a acessibilidade deve ser um direito de todas as pessoas, inclusive as que têm mobilidade reduzida, tornando obrigatória as mudanças arquitetônicas para que nenhum indivíduo tenha barreiras para a execução de suas tarefas. (ASSOCIAÇÃO BRASILEIRA DE NORMAS TÉCNICAS, 2015). 
Design universal aplicado no desenvolvimento... doméstica WERNER, E.; MARTINS, G. I.; MEDEIROS, I. L. de

O Design Universal é um elemento essencial na criação, desenvolvimento e utilização de um produto ou espaço inclusivo. Ele está diretamente ligado às políticas que visam atender a todos os usuários sem causar estranheza. 
Para Quaresma (2017), quando nos referimos às limitações, elas podem ser definidas como momentânea, temporária ou permanente. A limitação momentânea surge no momento em que você fica sem energia e no escuro, por exemplo. Nesse momento, você dependerá de outros fatores para sobreviver - tato, audição e fala. A temporária se refere às limitações por um período de tempo como as grávidas, que têm, por nove meses, seu corpo alterado e como consequência uma maior dificuldade para realizar tarefas que antes eram fáceis.

Um exemplo de limitação permanente diz respeito aos idosos, que podem perder habilidades físicas ou sofrer alterações na visão, audição, memória, capacidade de raciocínio e outras. Abberley (2013) parte do exemplo da artrite para lançar o argumento de que é preciso alargar o conceito de deficiência para outros grupos sociais, como idosos. Inúmeros casos demonstram que a deficiência não é uma experiência limitada a uma minoria reduzida, mas um fato ordinário e previsível no decorrer da vida das pessoas, assim como o envelhecimento.

O modelo de deficiência surge na década de 1960, Reino Unido, como reação às abordagens biomédicas. A ideia que embasa esse modelo social é de que a deficiência não deve ser entendida como um problema individual. Ela deve ser entendida como uma questão social, transferindo a responsabilidade pelas desvantagens dos deficientes das limitações corporais para a incapacidade da sociedade de prever e ajustar-se à diversidade (OLIVER, 1990).

Tendo em vista a importância da acessibilidade, o projeto atentou-se para desenvolver um produto que seja de uso equitativo. Neste sentido foram revelados aspectos da acessibilidade descrito pela ABNT de como podem ser feitas as rampas de acesso, os sinais que devem conter e as medidas exigidas para locomoção de cadeirantes. Todos esses pontos foram levados em consideração no projeto. 


\subsection{Dificuldades para o Cadeirante no Brasil}

Sabendo que ambientes privados não estão totalmente preparados para o uso equitativo, ressaltamos as dificuldades que os cadeirantes enfrentam quando falamos de locomoção, apesar de já existirem normas regulamentadoras para acessibilidade. A NBR 9050, divulgada em setembro de 1985 no Brasil trata-se da norma de "adequação das edificações e do mobiliário urbano à pessoa deficiente" (ASSOCIAÇÃO BRASILEIRA DE NORMAS TÉCNICAS, 1985, 2015).

A acessibilidade é um direito das pessoas, sendo assim, nenhum tipo de barreira deve impedir o acesso e locomoção dos cadeirantes já que isso compromete a autonomia dos mesmos, não somente impedindo o acesso aos locais, mas aos serviços ofertados pelo local.

Se já nos deparamos com a falta de acessibilidade em obras públicas, isso se expande para quando falamos de casas e produtos do dia a dia. Ter um portador de necessidades físicas em casa é sinônimo de adaptação para que ele possa viver sem restrições. Produtos como vasos sanitários, barras de apoio e cadeira de banho estão disponíveis no mercado, mas nem todos são de uso universal. Cadeirantes encontram dificuldades referentes a isso, principalmente quando dividem a casa com indivíduos sem limitações.

\subsection{Normatização de Banheiros para Cadeirantes}

Para melhor atender a indivíduos cadeirantes, a NBR 9050 (2015) estabelece critérios e parâmetros técnicos a serem observados em qualquer tipo de construção que deva contemplá-los. Segundo a norma, banheiros acessíveis devem prever área de manobra para permitir que o indivíduo tenha uma rotação de $360^{\circ}$. 
Para o box do chuveiro, as dimensões mínimas devem ser 0,90m por 0,95m. Também se recomenda a utilização de válvula termostática na instalação do chuveiro. A altura máxima a que deve estar posicionado o painel ou registro de ligar o chuveiro deve ser de $1 \mathrm{~m}$. Deve-se ter comandos que permitam ao cadeirante ajustar a altura do chuveiro conforme sua necessidade.

Se houver porta no box, essa deve ter um vão com largura livre mínima de 0,90m. É importante que o box não tenha trilhos a fim de não criar barreiras para o cadeirante.

O banco e os dispositivos de fixação presentes no banheiro devem suportar um esforço de $150 \mathrm{~kg}$.

A figura abaixo (fig. 2) mostra de forma representativa e sintética as medidas acessíveis para o cenário do banheiro.

Figura 2 - Etapas do Design Thinking aplicadas ao projeto

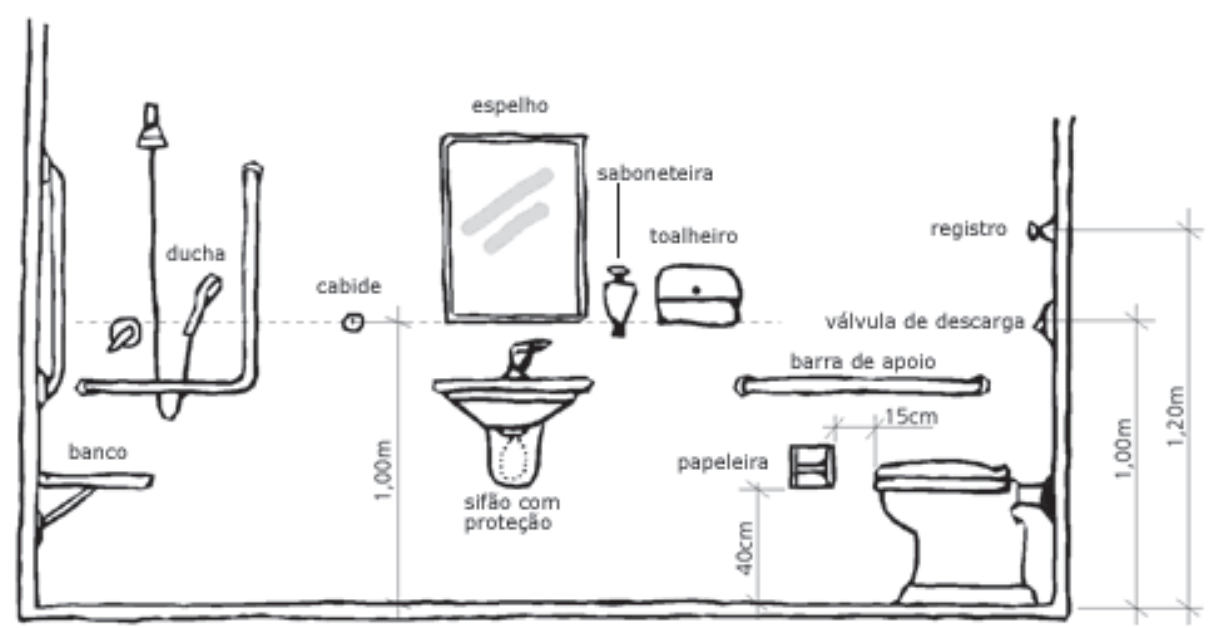

Fonte: dos autores, 2018. 
Design universal aplicado no desenvolvimento... doméstica WERNER, E.; MARTINS, G. I.; MEDEIROS, I. L. de

A acessibilidade é um direito das pessoas, sendo assim, nenhum tipo de barreira deve impedir o acesso e locomoção dos cadeirantes já que isso compromete a autonomia dos mesmos, não somente impedindo o acesso aos locais, mas aos serviços ofertados pelo local. 
O mercado de produtos para esse ambiente está em crescimento já que cada vez mais se busca tecnologias para atender indivíduos com particularidades. Com base nessas regulamentações, a proposta de projeto se atentará aos detalhes para que um cadeirante possa fazer a utilização do produto sem complicações.

\subsection{História e Evolução do Banho e Chuveiro}

Segundo Franceschi et al. (2013), a tradição de banhar-se surge já na antiguidade. Egípcios tinham a crença que o banho os fazia resistir às pragas do mundo antigo e tomavam banho todos os dias, assim como os romanos e persas. Para os gregos, o banho era um ritual sagrado de purificação e feito de forma pública. Na Idade média o banho foi abolido pela Igreja Católica pois acreditava-se que essa era uma prática pagã, existiam épocas específicas para que ele acontecesse. Segundo o autor, na Idade Moderna começou-se a associar a cura de doenças com o banho e foi só a partir do século XIX que essa voltou a ser uma prática normal.

O banheiro como conhecemos hoje passou a existir a partir dos anos de 1930. Após a Segunda Guerra banheiros começaram a ser comuns nas construções de todas as casas - o que não acontecia até então. Segundo Feijó (2007), a partir daí as casas começaram a ter sistema de água encanada e banheiro, possibilitando banhos mais seguidos.

Conforme o site História de Tudo, o chuveiro é o principal aliado do banho, ele se define por ter pequenos orifícios por onde a água sai de forma a economizar a água (HISTÓRIA..., 2018). A ideia por trás do mecanismo é bastante antiga: no Egito e Grécia Antiga já haviam produtos parecidos e o aquecimento da água era feito separadamente, por meio da queima de lenha. A partir de 1940, se difundiu no Brasil a ideia de chuveiro elétrico, o qual era formado por uma resistência feita por metais com altos pontos de fusão - que não se derretiam com facilidade - que era 
capaz de aquecer a água. Esse aparelho não era seguro já que não possuía isolação eficaz. A partir da década de 60 com o uso de plásticos, os chuveiros se tornaram mais agradáveis esteticamente e passaram a ter maior segurança.

Atualmente existem chuveiros com uma variedade muito grande de material. Variam desde modelos com plásticos até metais sanitários, além dos que possuem alta tecnologia. A imagem abaixo (fig. 3) mostra a evolução do chuveiro de 1900 até os dias atuais.

Figura 3 - Análise diacrônica do chuveiro

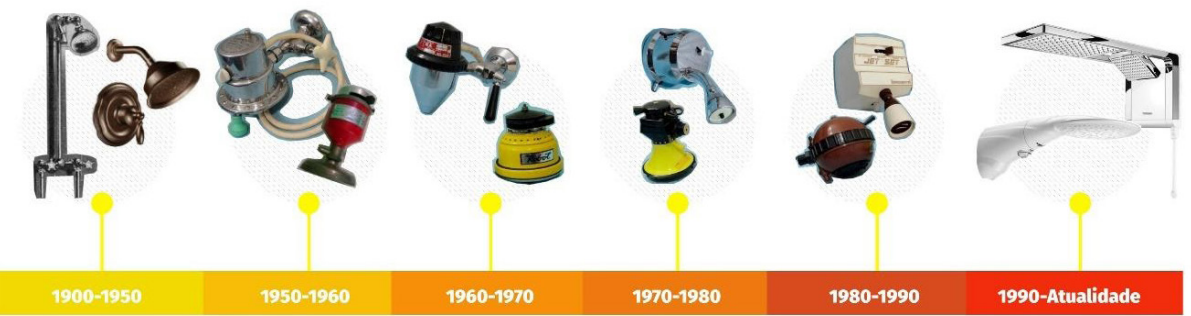

Fonte: dos autores, 2018.

Relacionando o presente projeto com a história do banho e chuveiro, percebe-se uma evolução cada vez maior numa simples ação. Com o avanço de produtos envolvendo o Design Universal faz-se necessário a criação de uma proposta inovadora nesta área. Pensando em indivíduos com limitações físicas ao tomar banho, pretende-se alcançar o melhor resultado quanto a sua utilização.

\section{DESENVOLVIMENTO}

\subsection{Público Alvo}

A primeira abordagem do processo de desenvolvimento do chuveiro foi estabelecer uma conexão com os problemas encontrados por cadeirantes no seu dia a dia. Desta 
maneira foi desenvolvido e aplicado um questionário de respostas fechadas. Este foi encaminhado por meio eletrônico, do período de 20 de agosto de 2018 até 03 de setembro de 2018. Essa etapa serviu como norteadora de projeto, identificando as primeiras oportunidades. Todos os 20 respondentes eram cadeirantes. No questionário procurou-se entender como é sua rotina e suas limitações dentro do ambiente doméstico por eles enfrentadas.

Dos questionados, vinte têm dificuldade de se locomover dentro do banheiro e de realizar suas necessidades fisiológicas. Todos os indivíduos possuem deficiência parcial. Apenas cinco dos questionados possuem a casa adaptada. Para quinze respondentes, os produtos de adaptação são esteticamente desagradáveis e realizam suas tarefas diárias sem auxílio de outras pessoas. Abaixo (fig. 4), uma imagem síntese da porcentagem resultante do questionário.

Figura 4 - Síntese do questionário
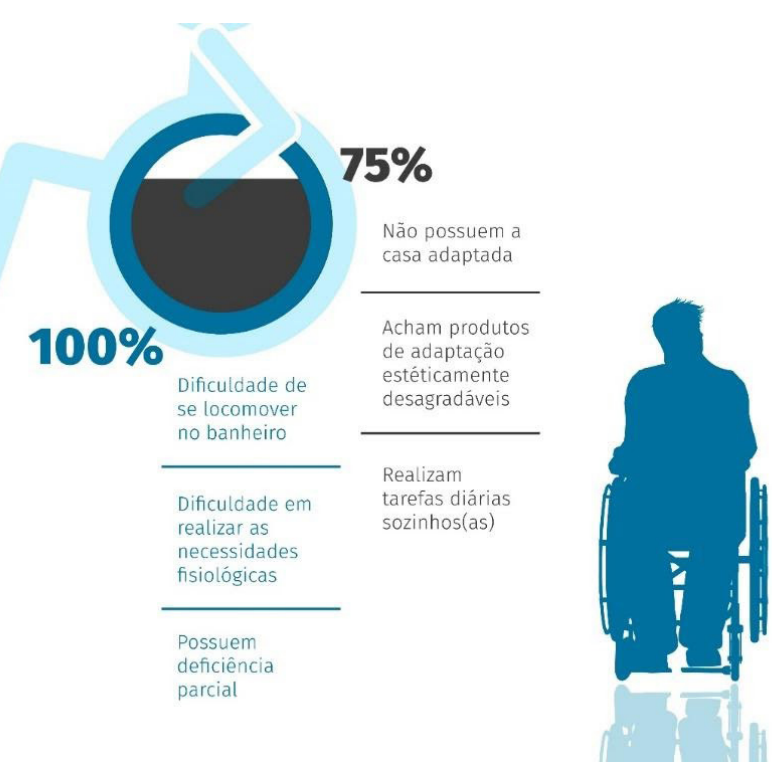

Fonte: dos autores (2018). 
Dos cadeirantes questionados percebeu-se uma busca por autonomia, mas quando submetidos a algumas ações cotidianas (lavar a louça, tomar banho) possuem grande dificuldades e por vezes dependem de outra pessoa para realizar a atividade. Também se constatou que o banheiro é o ambiente mais problemático. A partir disso, foi encontrado como oportunidade de melhoria a proposta de ducha doméstica inclusiva, já que o mercado carece dessa linha de artigos voltadas ao Design Universal.

\section{DUCHA DE BANHO DOMÉSTICA INCLUSIVA COMO SOLUÇÃO DE PRODUTO}

Com o resultado do questionário dois itens ganharam destaque: um deles se refere ao fato de que o cadeirante possui uma dificuldade maior de locomoção e realização de atividades no ambiente do banheiro - $100 \%$ dos questionados possuem essa problemática. O outro trata da estética de produtos destinados aos cadeirantes, estando ainda muito estigmatizada e ligada ao âmbito hospitalar, causando certo desconforto no uso do produto.

Devido a esses dois fatores norteadores, optou-se por trabalhar no ambiente do banheiro de modo a focar a atenção na melhoria da estética desse ambiente para que indivíduos cadeirantes se sintam mais confortáveis. Dentro desse cenário o produto foi definido por meio de observação realizada em pontos de venda de produtos inclusivos e questionário com cadeirantes. Na visita aos pontos de venda se percebeu que são inexistentes as duchas domésticas que possam atender ao usuário cadeirante de forma inclusiva - quando o produto é voltado para esse público, ele é totalmente estigmatizado ou pressupõe que o cadeirante seja dependente de outra pessoa. Para melhor exemplificar, o produto (figura 5) é vendido em lojas de produtos inclusivos, mas ao mesmo tempo não permite que o usuário cadeirante tenha autonomia sobre ele: se uma pessoa alta utilizar o chuveiro e deixar configurado para a sua altura, o cadeirante não alcançará o destrave para que o chuveiro possa deslizar à sua altura. Será, portanto, dependente de outro indivíduo. 
Figura 5 - Chuveiro com barra deslizante
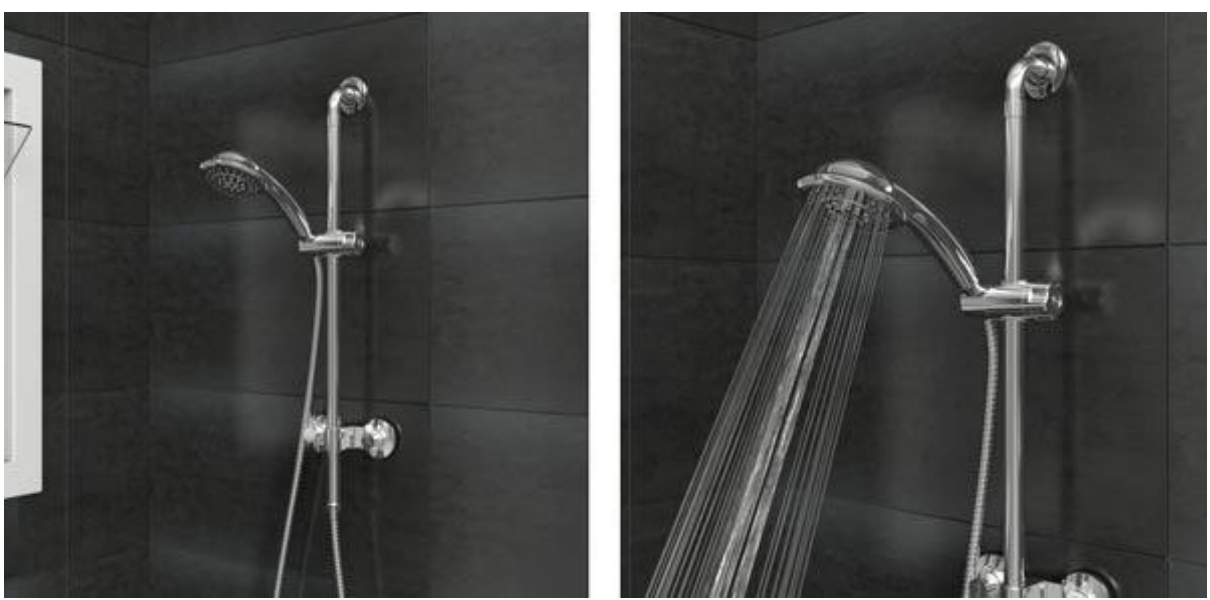

Fonte: Blukit (2018).

Conforme Salete - cadeirante que concedeu entrevista - sua casa não é adaptada e o banho é a atividade diária em que mais encontra dificuldade. Para realizar a ação, Salete utiliza uma cadeira de banho e uma ducha pequena (chuveirinho), já que divide a casa com pessoas que não possuem limitações físicas. Para a entrevistada os produtos que estão inseridos no mercado atualmente não são capazes de atender a ela e a seus familiares ao mesmo tempo.

\subsection{Painel Conceitual}

Segundo Reis (2009) a estética como conhecemos atualmente pode ser definida como "sensação". A estética do produto é um dos principais meios de comunicação do produto com o cliente, sendo essa as sensações que o mesmo consegue despertar no usuário. O designer tem a função de projetar produtos que sejam funcionais em termos técnicos, ergonômicos e sustentáveis, sem deixar de lado os fatores estéticos e simbólicos, a fim de atingir fatores emocionais, percebidos primeiramente pelo consumidor. 
O produto foi desenhado sobre o conceito do minimalismo representado na figura 6, com o objetivo de atingir uma estética simples e leve, se desprendendo dos produtos com estética hospitalar. O minimalismo é uma tendência que vem sendo aplicada constantemente e pode ser definida como redução das formas e elementos, a fim de produzir uma linguagem mais universal aos produtos.

Figura 6 - Painel conceito

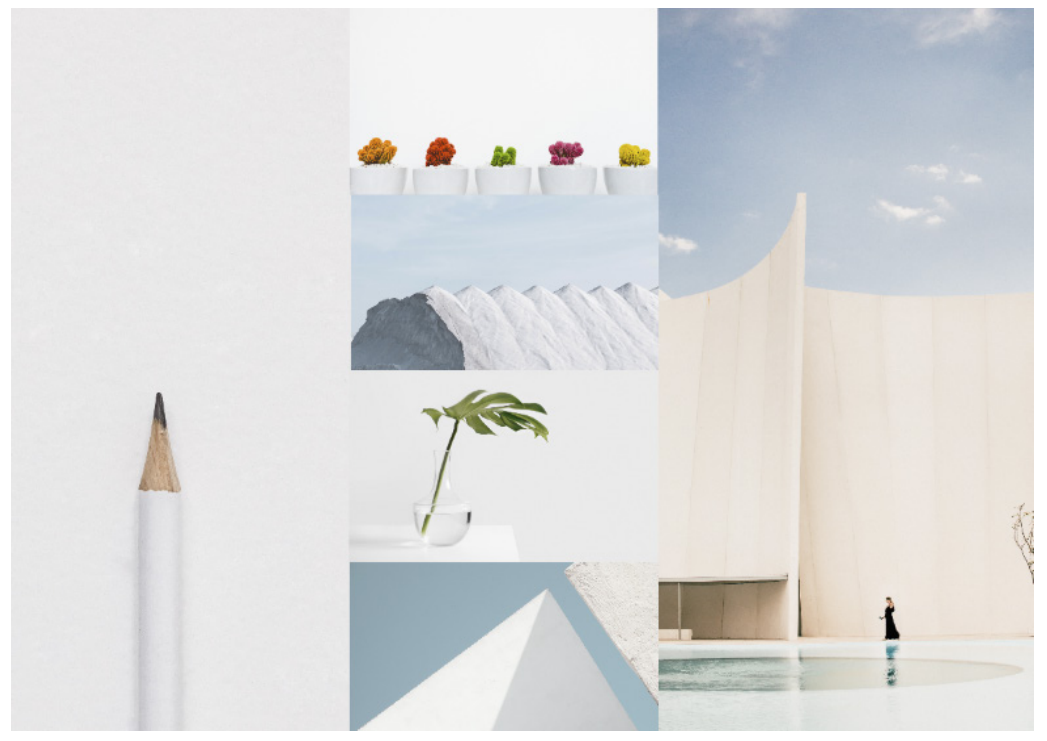

Fonte: dos autores (2018).

Tendo essa linguagem visual definida como diretriz estética projetual, as alternativas de soluções foram desenvolvidas respeitando o conceito, apresentadas na sequência.

\subsection{Alternativas (Rendering)}

As alternativas desenvolvidas para o produto foram embasadas em oito requisitos de projetos pré-estabelecidos a partir de pesquisa e questionário, sendo 1) 
minimalista, 2) automatizado, 3) ajustável, 4) resistente, 5) seguro, 6) fácil utilização e 7) higiênico.

Tendo definido os requisitos, se passou para etapa de criação onde foram desenhadas e pensadas em diferentes soluções de produtos. Para escolher a melhor alternativa foi aplicada uma matriz de decisão (pontuações feitas em forma de tabela para as alternativas) de forma a selecionar quatro modelos que mais atendiam aos pré-requisitos de projeto. A partir disso, as alternativas melhores pontuadas foram refinadas e redesenhadas no software photoshop, conforme figura 7.

Figura 7 - Alternativas finais de produto

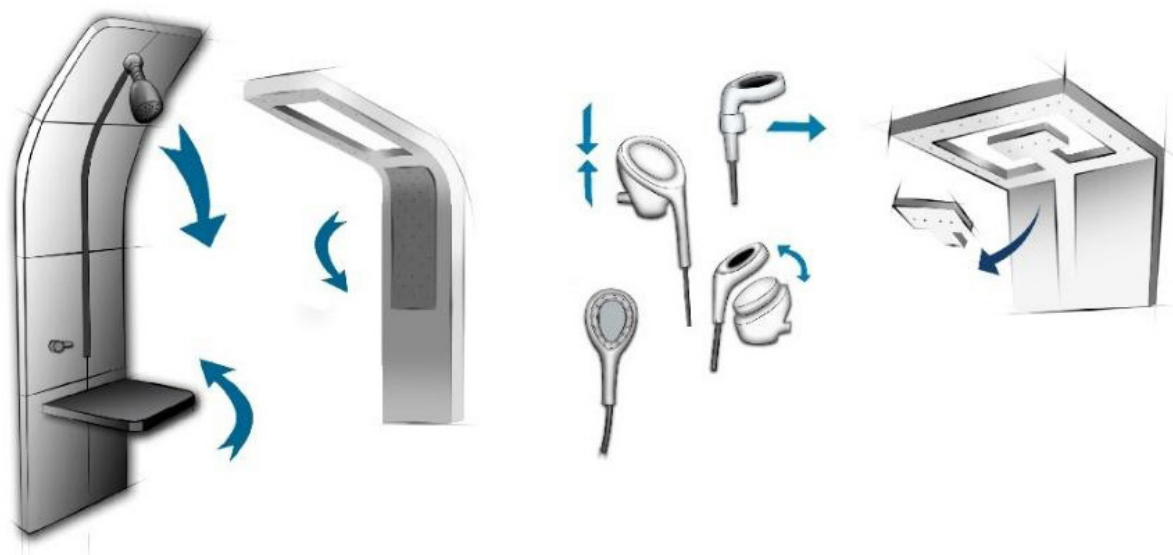

Fonte: dos autores, 2018.

A partir dessas quatro alternativas foi necessário fazer um último refinamento para que os pontos fortes de cada uma pudessem ser implantados em um só produto final (figura 8). 
Figura 8 - Alternativa final de produto

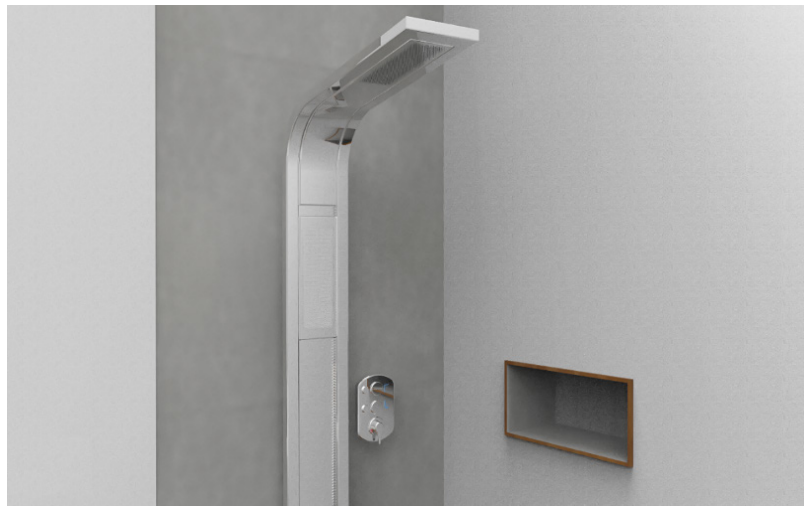

Fonte: dos autores, 2018.

Figura 9 - Peças do chuveiro
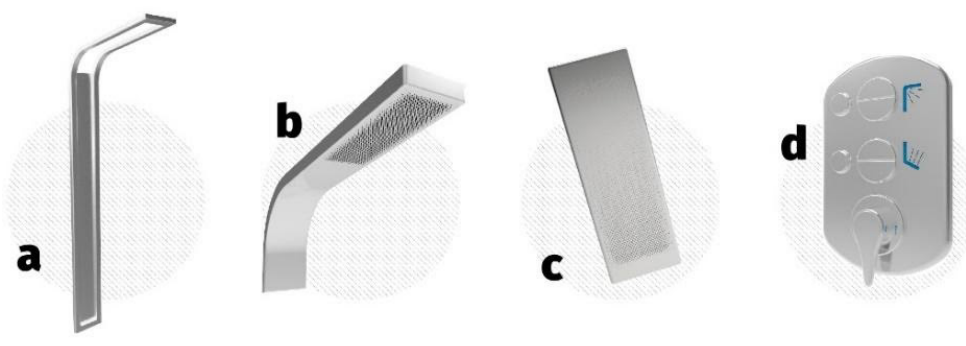

Fonte: dos autores, 2018. 
O chuveiro proposto é um produto que preza pela melhor experiência do usuário em sua amplitude. Embasado no termo bauhausiano "menos é mais", contempla objetos simples capazes de transformar aquilo que se entende por chuveiro nos dias de hoje. Mayim (do hebraico água) tem seu design minimalista refletido de forma moderna e harmoniosa em cada detalhe do produto.

Em resposta às problematizações encontradas no decorrer da pesquisa pode-se dizer que a proposta de projeto permite ao cadeirante tomar banho de forma autônoma. O produto desenvolvido com a preocupação de atender ao maior número de indivíduos é benéfico também para aqueles que não possuem limitações.

As grávidas, por estarem passando por uma limitação momentânea, têm sua capacidade de esforço reduzido: com isso, o chuveiro inferior com inclinação ajustável é capaz de proporcionar maior conforto nessa atividade diária.

A proposta além de inclusiva torna o banho do cadeirante mais seguro já que o chuveiro superior e inferior age conforme sua necessidade.

Para melhor ilustrar a utilização do chuveiro por esses usuários, se fez uma ambientação, conforme a figura 10.

Figura10 - Ambientação de grávida e cadeirante na utilização do produto.
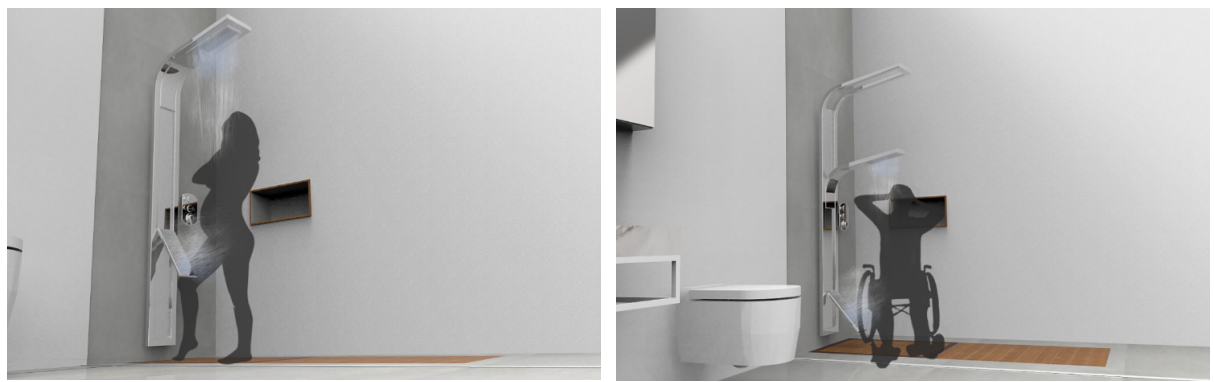

Fonte: dos autores, 2018. 
O chuveiro inferior faz com que o cadeirante não corra riscos enquanto se enxágua com sabonete. Quando o indivíduo tem algum elemento para segurar além de sua cadeira de rodas, barra lateral ou produtos de higiene, o banho se torna perigoso.

Conforme apontado em questionário, pelo menos 02 indivíduos já se acidentaram no banho.

\section{CONSIDERAÇÕES FINAIS}

Cadeirantes, grávidas ou idosos se sentem desconfortáveis socialmente ao utilizar produtos que foram feitos exclusivamente para eles, já que muitos projetistas se preocupam mais com a funcionalidade do produto do que com a estética propriamente dita. A estética é, porém, um fator essencial capaz de criar um laço entre o usuário e o produto. Quando o designer efetivamente integra a usabilidade de produto esse público não deve encontrar quaisquer barreiras para operá-lo.

A ducha doméstica, projetada de acordo com as dimensões exigidas pela NBR de acessibilidade, foi adaptada para melhor atender os mais variados públicos. Dessa forma, deixa de seguir o padrão estético e funcional até então estabelecido em duchas convencionais e traz uma nova perspectiva de como o design pode atuar de forma a deixar o produto mais universal.

Sendo assim, a resposta da problematização encontrada na pesquisa através do desenvolvimento de ducha doméstica inclusiva foi capaz de unir diversas funcionalidades em um só produto e qualquer pessoa pode utilizá-lo de uma maneira confortável e aconchegante. 
Projética, Londrina, v. 12, n. 1, p. 270-296, março 2021

Ressalta-se a importância do profissional de projeto construir empatia com o público desejado, seja por meio de entrevista ou observação.

Destaca-se também a importância de construção de protótipos para realizar efetivos testes de medidas e produzir melhorias no produto. Esse projeto propõe um olhar crítico para os objetos do nosso cotidiano e recomenda-se diversificar os estudos aqui aplicados. 
O chuveiro proposto é um produto que preza pela melhor experiência do usuário em sua amplitude. Embasado no termo bauhausiano "menos é mais", contempla objetos simples capazes de transformar aquilo que se entende por chuveiro nos dias de hoje. 
Projética, Londrina, v. 12, n. 1, p. 270-296, março 2021

\section{REFERÊNCIAS}

1. ABBERLEY, Paul. The concept of oppression and the development of a social theory of disability. In: Policies for Diversity in Education. Routledge, 2013. p. 245-259.

2. ALVARENGA, Flávia Bonilha. Uma abordagem metodológica para o projeto de produtos inclusivos. Tese (Doutorado em) - Faculdade de Engenharia Mecânica, Universidade Estadual de Campinas, Campinas, SP, 2006.

3. ASSOCIAÇÃO BRASILEIRA DE NORMAS TÉCNICAS. NBR 9050: 2015. Acessibilidade a edificações, mobiliário, espaços e equipamentos urbanos. 3. ed. Rio de Janeiro: ABNT, 2015.

4. ASSOCIAÇÃO BRASILEIRA DE NORMAS TÉCNICAS. NBR 9050: adequação das edificações e do mobiliário urbano à pessoa deficiente. Rio de Janeiro: ABNT, 1985.

5. BERTAK. Acessibilidade: croqui de um banheiro acessível. Disponível em http://bertak.com.br/acessibilidade-5-dicas/croqui-de-um-banheiroacessivel/. Acesso em: 29 nov. 2018.

6. BLUKIT. Chuveiro ducha 2 em 1 com barra deslizante. Disponível em https:// www.blukit.com.br/produto/detalhe/kit-chuveiro-ducha-2-em-1-com-barradeslizante. Acesso em: 29 nov. 2018.

7. BROWN, Tim. Design thinking. Harvard Business Review, Brighton, MA, v. 86, n. 6, p. 84-92, Jun. 2008. 
Design universal aplicado no desenvolvimento... doméstica

WERNER, E.; MARTINS, G. I.; MEDEIROS, I. L. de

8. BROWN, Tim. Design thinking: uma metodologia poderosa para decretar o fim das velhas ideias. Rio de Janeiro, RJ: Elsevier, 2010.

9. FEIJÓ, Bruno Vieira. As águas do tempo: a história do banho. Guia do Estudante, São Paulo, SP, 2007.

10. FLEURY, Maria Tereza Leme; WERLANG, Sergio Ribeiro da Costa. Pesquisa aplicada: conceitos e abordagens. In: WOOD JÚNIOR, Thomaz (coord.). Anuário de Pesquisa GV 2016-2017. São Paulo, SP: FGV-EAESP, 2016. p. 10-15.

11. FRANCESCHI, Marcello Teixeira; FREITAS, Mayara Mayner de; DAHER, Darline de Almeida Pinto; FERREIRA, Dayse Dellis; AZEVEDO, Luiz Felipe; DOMICIANO, Marcelo de Oliveira; VIANA, André Luiz. O chuveiro inteligente. E-Locução, Revista Científica da FAEX, Extrema, ano 2, ed. 3, p. 141-160, 2013.

12. FRANCISCO, Paulo César Moura; MENEZES, Alexandre Monteiro de. Design universal, acessi bilidade e espaço construído. Construindo, Belo Horizonte, MG, v. 3, n. 1, p. 25-29, jan./jun. 2011.

13. HISTÓRIA do chuveiro. Disponível em: http://históriadetudo.com/chuveiro. Acesso em: 28 nov. 2018.

14. MACE, Ronald; HARDIE, Graeme; PLACE, Jaine. Accessible environments toward Universal Design. In: PREISER, Wolfgang F. E.; VISCHER, Jacqueline C.; WHITE, Edward T. (ed.). Design interventions: toward a more humane architecture. New York: Van Nostrand Reinhold, 1991.

15. MUNARI, Bruno. Das coisas nascem coisas. Tradução de José Manuel de Vasconcelos. São Paulo: Martins Fontes, 1998. 
Projética, Londrina, v. 12, n. 1, p. 270-296, março 2021

16. NORMAN, Donald Arthur. O design emocional: por que adoramos (ou detestamos) os objetos do dia-a-dia. Rio de Janeiro: Editora Rocco, 2008.

17. OLIVER, Michael. The politics of disablement. London: Macmillan Education, 1990.

18. QUARESMA, Maria Manuela Rupp. A aplicabilidade do design inclusivo em projetos de design. 2017. 118 f. Dissertação (Mestrado em Design) - Pontifícia Universidade Católica - PUC-Rio, Rio de Janeiro, 2017.

19. REIS, Marcos Roberto dos. Fatores estéticos formais integrados ao processo de desenvolvimento de produtos. 2009. 152 f. Dissertação (Mestrado em Engenharia Mecânica) - Universidade Federal de Santa Catarina, Florianópolis, SC, 2009.

20. VILLELA, Flávia. IBGE: $6,2 \%$ da população têm algum tipo de deficiência. Agência Brasil, Rio de Janeiro, 21 ago. 2015. Disponível em: http:// agenciabrasil.ebc.com.br/geral/noticia/2015-08/ibge-62-da-populacao-temalgum-tipo-de-deficiencia. Acesso em: 8 nov. 2018. 